glands, and 1 probably originated in the ducts; 4 were duct carcinomata ; 1 duct papilloma ; 2 acinous carcinoma ; 1 adeno-carcinoma, and 1 was returned as sarcoma by one pathologist and carcinoma by another ; 1 was colloid.

In conclusion, my thanks are due to the medical men under whose care the patients have been, and to Mr. A. T. Longbotham, the Superintendent Registrar of Births and Deaths, without whose help I should not have been able to trace as many of the cases as I have done.

$$
\text { REFERENCE. }
$$

1 Lancet, September 18th, 1909

\section{THE TREATMENT OF CHRONIC DUODENAL ULCER.}

\section{By E. C. HORT, F.R.C.P.EDIN.*}

In the last three years it has fallen to my lot to be directly concerned in the treatment of over 70 cases of gastric and duodenal ulcer, mostly in the chronic stage. Of this number, 24 have been diagnosed as duodenal by myself and other physicians. I venture to hope, therefore, that a very brief summary of what experience has taught me personally in these cases may illustrate one or two of the points raised by this debate.

In the past our surgical colleagues have undoubtedly had cause for complaint that often we have not invoked their assistance sufficiently early. To-day, with no uncertain voice, we are told that all chronic cases of duodenal ulcer should be submitted to operation as soon as diagnosed. But, before counselling our patients to seek the aid of the surgeon, we may surely inquire:

1. If the eventual results of operation, especially of the posterior no-loop variety, are as uniformly good as the immediate issues sometimes appear to show.

2. If we yet know sufficient of the essential nature of the disease itself to justify us in making ex cathedrâ statements as to what in these cases is the correct treatment to adopt.

3. If it is really true that medical science can do little to avert the necessity for what must always, even granting a low operative mortality, be a somewhat formidable procedure.

1. With regard to the first of these inquiries, it happens that in the last few months there have been sent to me 5 cases of duodenal ulcer which had been submitted to operation. In each case the surgeon was a man of high reputation in connexion with recent developments in gastric and duodenal surgery, so there can be no question of the degree of surgical skill involved. Very briefly these are the results :

The first patient, operated on twenty months ago, says: "Since the operation I have had no real peace or relief. My general health is perhaps improved, but I have the old pain always."

The second, operated on last winter, says he cannot believe the ulcer is really healed. He never had vomiting until after operation and then not for many weeks. He now has gevere pain at the old site and at the point of junction.

The third, operated on eighteen months ago, is in a lamentable condition, with frequent attacks of severe pain, sometimes melaena, and constant distress from an aggravated form of melaena, and constar

The fourth had an alarming attack of malaena several months after operation, and intermittent pain in the left subcostal area. The fifth, operated on nearly two years ago, had recurrence lately of pain and haemorrhage, and, in addition, uncontrollable retching and sometimes vomiting when the hand is laid even gently on the abdominal wall.

I have in addition notes of 3 gastric cases short-circuited for ulcer presenting a similar history.

In these cases, and in the gastric ones, ulceration has apparently persisted or recurred, and in most there is the additional distress caused by the profound disturbance in the mechanics and hydrostatics of stomach and bowel caused by the new connexion. Viewed from any standpoint, the post-operative condition now is a most difficult one to deal with, as I find all treatment practically useless, beyond temporary relief of the associated catarrh

* The author was asked to take part in the discussion on the treatment of duodenal ulcer opened by Mr. Moynihan at a meeting of the Surgical Section of the Royal Society of Medicine on 1909), but was una,oidably prevented from being present. The remarks which Dr. Hort intended to make are embodied in this paper.
So much so, that I now decline to undertake the treatment of such cases.

It would of course be most unfair to quote a few isolated cases of failure of relief by operation, and from them to belittle the brilliant work of Mr. Moynihan, the Mayo brothers, and their colleagues. But it is most unlikely that mine has been a solitary experience, and the question arises if operation may sometimes perhaps be undertaken unduly early as well as unduly late. However this may be, an impression remains that a considerable time should elapse after operation before one can judge of the likelihood of permanence of results.

2. That we know absolutely nothing of the essential nature of the origin of duodenal ulcer few will deny, however much we may think we know of the causes of the maintenance of their patency. But-and the question is of more than academic interest-the problem whether duodenal ulcer is a disease sui generis or a mere symptom only has a most direct bearing on the question of surgical intervention. If it be a disease bearing no particular relation to other observed incidents in the lifehistory of the alimentary canal, universal excision of the ulcer, or of a cylinder of duodenum bearing the ulcer, as urged by Mr. Moynihan and his followers, would be on a similar footing to removal of a lipoma, and equally commendable. If, on the other hand, ulcer of the duodenum be only a symptom of a general disease, as yet unidentified, bearing very close relations to other ulcerative lesions in the whole alimentary tract, the matter assumes a very different aspect. Let us consider for a moment what these relations are.

Ulcer of the duodenum is very often a multiple lesion; it is frequently associated with a similar lesion on the other side of the pyloric gate; it is, as I have often had occasion to note, often associated with ulcers, sometimes of great depth and extent, in the tongue, gums, or cheeks; it is not by any means unknown in association with ulceration of the oesophagus; it has an inveterate tendency to recur, often through a long series of years; and, finally. there is hardly any toxaemic condition in which it may not occur as a purely symptomatic event. What can all this mean except that solitary or multiple ulcers of the duodenum are a locsl expression of some dyscrasia, we know not what, though my original suggestion of a floating mucolytic (gastrolytic or duodenolytic) poison is gradually gaining ground?

If only a fraction of this collateral reasoning be sound, how can the mere excision of a symptomatic lesion ensure the cure of the disease? It is as if by amputating a foot with a perforating ulcer one could eliminate the spirochate, restore the integrity of trophic neurons, and prevent recurrence of ulcer in the opposite limb. So long as the anknown factor originally responsible for the appearance of an ulcer be present, so long will the ulcer tend to recur. If we could be sure that that factor were no longer present surgery could offer much, and the fact that operation is often followed by the happiest results is strong evidence in such cases of the disappearance of that factor. In such event it can only be supposed that, the exciting cause being gone, natural cure is made possible from exclusion from the lymph stream, by cicatrization, of the ulcer's base and sides. In such cases, therefore, there is for surgery a quite legitimate field.

On the other hand, the frequency of recurrence and of co-existence of multiple ulcers in different sections of the canal as well as near the primary focus is strong evidence of persistence or reappearance, in numerous cases, of the unknown factor. In the untreated disease we often see acute phases of suffering interspaced by considerable periods of relative or absolute ease. In quiescent intervals we have evidence that sometimes the lesion never completely heals; and yet it is only at times, often associated. with some lowering of general health, as from anxiety and strain, or at certain seasons of the year, such as spring and autumn, that manifestations of activity occur. In all such cases the eroding influence of digestive fluids from the secreting glands in stomach and bowel, and from leacocytes and other tissue cells, is always present so long as the ulcer remains. Hence there must be some other factor to account for the transition from quiescence to activity. Surely, therefore, it is not unreasonable to surmise that renewed activity may be due, inter alia, either to a fresh activity of specific poisons or to the fact that they have 
never vanished. Looked at in this way, how essential it becomes to make every effort to bring the nutritional factor to the maximum point of efficiency, not only in order to promote local'repair, but to increase the general resistance against the essential cause of the disease! This will not necessarily be effected by excision or by short. circuiting, but by the more rational methods to which I will now briefly refer.

3. As regards medical treatment, many cases of duodenal ulcer, both acute and chronic, recover, and recover completely, under the medical régimes of starvation, semistarvation, the milk, egg, and slop treatment, the Lenhartz diet, and so forth. It is also true that many of these cases relapse. In hospital patients almost any method may be followed by rapid and striking improvement, mainly on account of the change from a wholly indiscreet dietary indulged in before admission. The value of all statistics based on treatment of this class of case is, therefore, seriously discounted. So little is this sometimes realized that I have been assured by physicians of wide hospital experience that new medical methods of treating gastric and duodenal ulcer are hardly wanted. This view, based on the experience that the hospital class do well under the time-honoured régimes of starvation followed by slops, is a very one-sided view, quite apart from the fact that a vast number of these cases relapse. For since 1907, when two small papers appeared under my name advo. cating a broader conception of the pathology of the disease than is generally taught, and urging the trial of treatment on somewhat novel lines, I have been concerned in applying, directly and indirectly, the principles there enunciated to more than 200 cases of ulcer of the stomach or duodenum. The demand, therefore, for a somewhat more effective medical régime than the ones I have mentioned has not been small. Further, as the great majority of these have been private cases, the question of grossly inappropriate diet before treatment does not apply as in the case of patients of the hospital class.

The treatment I adrocated was this:

For acute cases, with haemorrhage, subcutaneous injections of sterile normal horse serum and feeding by the mouth at the very earliest opportunity with small dry meals, mainly of meat.

For chronic cases, full meat diet in an appropriate form from the start, with repeated oral dosesnever on an empty stomach-of an antilytic serum specially prepared.

None of the duodenal cases treated by me, alone or in consultation, were recent ones except one. All were private cases. Every one was a derelict of some other method of treatment, and some were of ten, fifteen, and even twenty years' standing. Of these 24-this number not including the surgical cases referred to-there have been 2 that showed a very temporary tendency to relapse, and 1 failure that was unable for domestic reasons to persevere with the treatment. The test, therefore, has been a very severe one, though I shall call none of them cures till at least three jears have elapsed.

The relief of pain, haemorrhage, hyperchlorhydria, and dyspepsia has in all cases been most striking.

The history of the gastric cases is equally good, though with the greater number of cases the failures have naturally been more numerous. I am anable to attribute these results to the meat diet alone, as in three controls in which I withheld the serum for a fortnight progress was absent until the serum was added.

The rationale of $\mathrm{mg}$ treatment is briefly as follows :

1. If it be true that duodenal ulcer is a symptom and not a disease, the absorption of adequate protein in suitable form cannot but increase the resistant powers of the body as a whole to the unknown determining cause of the dise

local repair must certainly be assisted thereby. 2. If protein food is presented to a case of ulcer in which we
know that the digestive fluids exhibit a high degree of peptic and tryptic avidity, a certain proportion of these peptic and tryptic molecules will be saturated by the protein. If now, at the height of digestion, be added a serum with a high antipepsin and antitrypsin content, some of the unsatisfied residue of peptic end tryptic bodies will combine therewith, and the ulcer itself thus be indirectly shielded by diversion of these bodies.

3. Once more if an ulcer is congtently being bathed in aecreion tions laden with trypsin and other proteolytic ferments set free bacteris the bacteria, the administration of.a serum charged with antipeptic, value. That is to say, the eroding activity of ferments from these sources must to a great extent be kept in check by such cram. That this is not a matter of theory only can be proved bF any by any one who cares to treat a superficial ulcer which is conexpedient of dressing it with sterile gauze soaked in sterile normal serum.

Whatever the rationale of this treatment the clinical results are undeniable, and though at first it met with quite legitimate scepticism, doubt is rapidly giving place to inquiry, inquiry to trial, and trial to conviction. Making every allowance, therefore, for personal bias and inevitable failures, I feel justified in adding my testimony to that of those who declare that the medical treatment of duodenal ulcer is approaching a sounder basis than it has perhaps reached in the past.

\section{THE POOR LAW AND THE MEDICAL PROFESSION.*}

By the LATE JNO. MILSON RHODES, J.P., M.D., ALDERMAN OF THE CODNTY PALATINE OF LANCASTER.

When I was informed that you had done me the honour of inviting me to address you, much as I appreciated your kindness, I felt that I was, I will not say between the devil and the deep sea, for I would not for one moment venture to think either of you as the guardian of the former but that as a member of the profession form Com comittee for England and Wales, I was between the Scylla of the profession and the Charybdis of Poor Law administration. Probably under those circumstances the best course in my position to.day will be to imagine myself on the bench, and to do my best to well and truly try and true deliverance make between those who wish to reform the Poor Law and those who propose under the sole and not very courteous heading "to smash the guardians." That the report, or perhaps it would be more correct to say the cen reports, will receive the unanimous approval of the country I do not for one moment believe. That the Royal Commission has collected an enormous amount of information I cheerfally acknowledge, but they appear to have been too much divided among themselves to issue one common sense report, and, as regards some of the reports of the special investigators, from what $I$ have scen efor value is-well, not very greatly due to work of bed rock knowledge. All the same the report is of considerable value, but so far as medical assistance is sored the whole credit is most probably due to Dr. Downes, the only member of the profession on the Com. mission, and I am afraid the only member who had a thorongh practical acquaintance with the urban and rural unions Considering the splendid work he has accom. plished, not only in regard to the Commission, but also in regard to the reform of the workhouse dietaries and workhoure nursing, it is a wonder that his services have not long since received that acknowledgement which they richly deserve. His memorandum and his evidence before the Commission are oases in the arid desert littered with the notions of the charity cranks and the Fabian faddist."

Before dealing with the strictly medical aspect of the question allow me for a minute to direct your attention to que "Statistical Memoranda Relating to Public Health and Social Conditions." No more valuable Blue Book has beenissued in the thirty years that I have been connected with the Poor Law.

That report shows that the general death.rate in the last half century has fallen from 20.8 to 15 per 1,000 , a loss of at least 100 cases of sickness per 1,000 to the medical profession ; but the coster, hawker, the general labourer, and the innkeeper and the publican still have a death-rate of more than double that of the engineer, clerks, etc. As you ere of pauperism for England are all dou hastitutional treatment of disease has enormously increased; the Commission recom mend that we should copy our friends the French and mor our present term Poor Law, "Assistance substitute for our present tance." I do not think it will make much difference as regards the sick. There has

* The peper was read before the Manchester (South) Division of the * The paper was read before the author's death. 